\title{
Why Is Post-Conflict Rehabilitation Important for Preserving and Developing Transatlantic Relations
}

\section{Plamen Pantev*}

Preserving and developing transatlantic relations has proved to be an indispensable tool for handling the various challenges of global international relations, both in the past century and in the first years of the present one. The attraction of membership in NATO for countries that are still undergoing the process of post-conflict rehabilitation activities, the accession of new members to the Alliance from the former Soviet bloc, the examples of vitality and institutional modernization by the North Atlantic organization itself are significant arguments in this direction. Whatever the differences within the transatlantic community have been in the past and are at present, preserving and developing relations between Europe and North America have no substitute in terms of guaranteeing the democratic trends and stability in the world. There are allies, partners, friends of the transatlantic community, but they do not play a substitute role in promoting the progress of human civilization. Making the world safe for global economic activity, a place where human rights and dignity matter, is the heart of the transatlantic philosophy and construct.

Post-conflict rehabilitation activity is just one of the areas that has a crucial stake in keeping and upgrading the transatlantic relationship. However, it is becoming ever more important.

First, the need for effectiveness in international security relations shows that the durability of peace after intra-state or inter-state conflicts is linked not just to an efficient peace-enforcing and peacekeeping operation, but also to the level of democratization of the conflict-stricken societies, to the success of the institution-building process, security sector reform, disarmament of the conflicting sides, the return of refugees, and to the social and economic progress that is made after the end of the hostilities. All these activities are becoming already part of a forward-directed approach to conflict prevention. Both Europe and North America are interested in effective conflict-prevention results. Is there a single government of the transatlantic region today that is not interested in the success of the post-conflict rehabilitation efforts of the Coalition Forces in Iraq, including the creation of a secure environment in this country and in the region of the Greater Middle East? It is certain that no country of the transatlantic community would profit from the degradation of the situation in Iraq, but all will succeed if stability and economic vitality are restored. One of the important lessons of the Balkan post-conflict rehabilitation process has been that success would not have been possible without a working transatlantic cooperation mechanism.

Second, in the wake of conflict, war-torn societies are an especially attractive potential milieu for promoting and creating terrorist activity. Resolute steps toward rehabilitating these societies should prevent this from happening or intensifying. It would

* Dr. Plamen Pantev directs the Institute for Security and International Studies. 
be interesting to consider the Iraqi case from this perspective. There were opinions before the war in Iraq that the result of the U.S.-led coalition's intervention would lead to intensified terrorist activity. The alternative view was that the intervention was directed toward the pacification of a dictatorial regime that sooner or later would have openly staged the same activity that terrorists already carried out. There are clear difficulties in implementing post-war rehabilitation in Iraq while a mounting Al Qaeda terrorist struggle adds to the resistance being promoted by remnant elements of the regime of Saddam Hussein. But only a success by the international community in post-war rehabilitation in Iraq would deprive the Islamist-driven terrorists, especially Al Qaeda, of the argument that the Muslim world is doomed to never catch up with the rest of the civilized democratic world. The success of democracy and the market economy in Iraq is in the interest of the transatlantic community in its fight on terrorism. So, post-conflict rehabilitation bears a strong counter-terrorist aspect too - an aspect that the transatlantic community cannot neglect, especially when diverging perspectives pull the countries of the community into different positions in critical periods of international relations.

Third, facing the reality that, at the present day, international institutions have little or no capacity for sustaining, coordinating, and practically implementing crisis management, peacekeeping and peace-building activities, even when the needs for these efforts are most glaring, transatlantic cooperation and solidarity is an indispensable method of coping with this issue. While in the case of the Balkans the transatlantic community has arrived at solutions without major difficulties by shifting responsibilities (and also by orienting the futures of the nations of South East Europe toward the European Union and NATO), post-conflict sites in other regions of the world are not that lucky. The vehicle of transatlantic relations is the leading potent factor that could organize the efforts dedicated to dealing with the security, economic, social, and political distress of the post-war societies of the Greater Middle East, Africa, and Asia. It would include not only identifying the donors of economic help but also support humanitarian organizations to carry out their activities and organize security stabilization efforts. Transatlantic cooperation is crucial for involving, motivating, facilitating, and supporting all other international institutions that possess any ability to contribute to post-conflict rehabilitation.

Finally, post-conflict rehabilitation is important for transatlantic relations from both a theoretic and strategic point of view: no conflict should any longer be approached without a clear vision of where to drive the developments after the hostilities end. Definitely this is an ambitious task that neither the U.S. nor the EU is able to carry out alone on a global scale. The challenge facing both the U.S. and the EU in solidifying their global roles is how to define their cooperative attitudes towards each other in outlining their post-conflict rehabilitation activities. The task is ambitious, since postconflict rehabilitation is an extremely broad effort, encompassing social, political, security, military, economic, and financial activities. For example, humanitarian aid, security sector reform, and economic reconstruction are just parts of the more systematic effort defined as post-conflict rehabilitation. Considering the immensity and high costs of the task on the one hand, and the persisting budget limitations for every international 
actor on the other, the implementation of this post-conflict management tool requires above all the economic support of both the United States and the European countries. Transatlantic cooperation could be the vehicle and the driving force in attracting the world's capabilities in coping with post-conflict rehabilitation tasks.

In conclusion, there is no doubt that post-conflict rehabilitation requires transatlantic solidarity, but the very transatlantic relationship could overcome its moments of difficulties and doubts by utilizing the cooperative potential of the post-conflict rehabilitation effort itself. A better study of the unique opportunities provided by this indispensable human activity is more than necessary. 